\title{
Influence Factors of the Urban-rural Residents’ Income Gap: a Restudy with the Digital Inclusive Finance
}

\author{
Xiaoling Song, Hongyue Guo \\ Business School, Beijing Language and Culture University, Beijing, 100083, China
}

Key words: Digital inclusive finance, Urban-rural residents’ income gap, Panel data model.

\begin{abstract}
By incorporating Digital Financial Inclusion into the paper and applying the panel data of 31 provinces from 2011 to 2015, the author has made another inspection on the influential factors of income gap between urban and rural residents. Results show that, the development of Digital Financial Inclusion can obviously narrow the income gap between urban and rural residents. Factors of urbanization, industrial progress, mechanism and economy also have magnificent impacts. China should continue to deepen the practice of Digital Financial Inclusion, improve the construction of integrated platform and credit mechanism, carry out efficient supervision and preferential policies, improve the external environment of Digital Financial Inclusion, further to commonly realize the poverty reduction.
\end{abstract}

\section{Introduction}

Digital Financial Inclusion refers to all actions promoting the inclusive finance by digital financial services. By fully applying the digital technologies, it offers a series of regular financial services in a responsible and sustainable way. Since the reform and opening up to the outside world, binary urban-rural economic structure has always troubled the economic development of China. In the rural and low-income areas, there are serious phenomenon of financial threshold and exclusion. Financing difficulty is a long-standing issue. In the past, the income gap between urban and rural residents remained high for a long time. To neglect the income gap of economic growth will intensify social conflicts, which is bad for harmonious development. With the development and communication of Digital Financial Inclusion, it is hopeful to relieve the contradiction. To explore the influence of Digital Financial Inclusion has important significance for the balanced development of urban and rural areas in China.

\section{Influential Factors and Mechanisms of Income Gap between Urban and Rural Residents}

There are many factors influencing the income gap between urban and rural residents, including Digital Financial Inclusion, mechanism, policy, economic development, urbanization, dual economic structure, financial deviation, industrial structure, etc. By incorporating Digital Financial Inclusion into this paper, the author mainly explores the influential factors of income gap between urban and rural residents and mechanism from four aspects.

\section{Digital Financial Inclusion}

By relying on the big data, cloud calculation, mobile interconnection, Digital Financial Inclusion has expanded the coverage area of financial services, solved the problem of exclusion and developed the long-tail customers from three aspects: increase the reachability, cut off costs and intensify the risk control. By the threshold effect, poverty reduction effect and exclusion effect of traditional inclusive finance, it has impacts on the resident income and economic development, further to shorten the income gap between urban and rural residents. Essentially, influence of Digital Financial Inclusion on income gap between urban and rural residents is based on the intensity of traditional inclusive 
finance, further to enlarge the impacts on shortening the income gap between urban and rural residents from all aspects.

\section{Factor of System}

The impacts of system factor on the income gap between urban and rural residents are mainly embodied in financial expenditure bias, population structure and educational popularity.

In theoretical circle, it basically comes to an agreement that financial expenditure proportion enlarges the income gap between urban and rural residents. Financial expenditure has urban tendency. In order to realize the economic growth goal, the local government must spend a lot on the city and incline to the city from the aspect of financial policy. In this paper, the author considers that financial expenditure bias should have positive influences on the income gap between urban and rural residents. However, the financial expenditure structure should be improved.

\section{Economic Development and Opening up Degree}

Economic development has direct and obvious impacts on the national income. Judging from the domestic situation, the increase of marketing economic efficiency has undoubtedly and tremendously improved the national income. However, due to the differences between urban and rural level of productive forces, and also wrong industrial structure, regional differences have become more and more obvious. In the market with fierce competition, different productive effects make the elements to gather in cities. There are capital outflows in rural areas. The original low-income regions are eliminated in fierce competition. Consequently, the income gap between urban and rural residents has been enlarged.

\section{Progress of Urbanization and Industrialization}

Urbanization promotes the flow of labor forces, which can both increase the competition in urban labor market, cut down the wages of urban labor forces, reduce the surplus labor force, and also increase the labor productivity and income level. Meanwhile, elements will transfer to non-agricultural sectors with quite high marginal productivity. The increase of non-agricultural structure ratio will shorten the income gap between urban and rural residents.

\section{Model Design and Empirical Analysis}

In this paper, the author plans to adopts the panel data of 31 provinces from 2011 to 2015, further to set up a panel model including the cross section and time sequence.

\section{Selection of Variables and Data Specification}

\section{Explained Variables: Indicator of Income Gap between Urban and Rural Residents}

To measure the income gap between urban and rural residents, the most common indicator is per capita disposable income ratio of urban and rural residents. It is quite easy and intuitive to acquire data. Most domestic scholars apply this method in literature. However, this computing method cannot express the impacts of population changes of urban and rural areas. Comparatively speaking, Gini coefficient and Theil index are more complicated and rigorous. Theil index takes the factor of population change into consideration, which can decompose the income gap of urban and rural residents into intra-block gap and inter-block gap. Therefore, the author selects Theil index to calculate the income gap between urban and rural residents. The bigger result represents bigger income gap between urban and rural residents. The formula is as shown:

$$
\mathrm{GAP}=\sum_{\mathrm{i}=1}^{2}\left(\frac{Y(\mathrm{i}, t)}{Y t}\right) * \operatorname{Ln}\left[\left(\frac{Y(\mathrm{i}, t)}{Y t}\right) /\left(\frac{X(\mathrm{i}, t)}{X t}\right)\right]
$$

In 2013, the Bureau of Statistics updated the method to calculate the income of urban and rural residents. In order to keep the data calculated by Theil Index consistent in dimension, but maintain 
the tendency as well, the author adjusts the ratio of income of urban and rural residents on old basis in 2011 and 2012, and then makes calculation. The adjustment method is as follows:

Of which, I' refers to per capita disposable income of urban and rural residents on new basis; I refers to the per capita disposable income of urban and rural residents on old basis; AGR refers to the average annual growth rate of per capita disposable income of urban and rural residents on new (from 2013 to 2015) and old (from 2011 to 2013) basis.

Explanatory Variable

(1) Digital Financial Inclusion Indicator. In July, 2016, based on the data offered by Internet Finance Research Center of Peking University and Ant Financial Services Group, the author sets up the Digital Financial Inclusion Indicator System from three dimensions, respectively are coverage width, usage depth and degree of digital supporting service; and also compiles three-layer Digital Financial Inclusion Indicator of 31 provinces and cities, 337 prefecture-level cities and 1754 counties. By referring to the research results, the author selects the calculated provincial Digital Financial Inclusion Indicator from 2011 to 2015 as the explanatory variable in the model to be constructed.

(2) Urbanization Ratio (URBAN). Binary economic structure, all kinds of administrative and economic methods have largely limited the labor mobility between urban and rural areas in China. With the progress of urbanization and improvement of policies, labor mobility has been gradually reinforced. The competition of urban employment market has been intensified and the average salary has been lowered. Meanwhile, the problem of rural surplus labor forces has been relieved and the income level of rural residents has been improved.

(3) Industrial Structure (IS). In this paper, the author selects the proportions of the secondary and tertiary industrial added values to GDP to signify IS, and also predicts that IS can shorten the income gap between urban and rural residents.

(4) Opening-up Degree (OPEN). The author selects the proportion of total import and export of foreign investments (The US dollar exchange rate against the RMB of that year)to GDP to signify OPEN.

(5) Financial Expenditure Bias. Too large financial expenditure bias will enlarge the income gap between urban and rural residents. However, the increase of expenditure for supporting agriculture will possibly reverse the trend, further to have positive impacts on weakening the income gap between urban and rural residents. Thus, the author selects the proportion of Financial Expenditure to GDP (FE) to signify the situations of financial expenditure, the proportion of expenditure for supporting agriculture to total financial expenditure (AFE) to signify financial expenditure structure. It is expected that, FE has positive impacts on the income gap between urban and rural residents, thus the coefficient should be positive. The coefficient of Financial expenditure for supporting agriculture (AFE) might be negative. Data of financial expenditure for supporting agriculture should be calculated by local financial expenditure for agriculture, forestry and water resources.

(6) Economic Development Degree (RGDP). Some people believe that poor population will benefit a lot from economic growth, further to realize poverty reduction. Some researches prove that GDP growth will enlarge the income gap between urban and rural residents. Currently, Chinese residential income level has not yet achieved the inflection point. Therefore, RGDP must have impacts on the income gap between urban and rural residents. However, it has to be examined that what the influential orientation is, and whether the economic development of China has already achieved the inflection point of "reversed U" curve. In this paper, RGDP is expressed by the GDP of local residents (unit: 10,0000 RMB).

\section{Design and Construction of Panel Model}

\section{Construction Method of Model}

In order to analyze the influences of the above 4 factors and 7 variables on the income gap between urban and rural residents, the author selects the panel data of 31 provinces from 2011 to 2015, takes the Theil index of income gap between urban and rural residents as the explained variables, the digital financial inclusion as the explanatory variables, and then sets up the regression model to make empirical analysis. 


\section{Unit Root Test}

By taking the raw data to carry out unit root test, results show that GAP, DIFI, OPEN AND RGDP is first order stable. URBAN, FE, AFE AND IS are first order unstable. After processing it by logarithm, results show that all are stable.

\section{Model Estimation Method}

In order to make estimation by fixed effect or random effect, it needs to carry out Hausman test on the model to be set. Test shows that, Model 1) and 2) should select the fixed effect model. Model 3) should select the random model.

\section{Empirical Result and Analysis}

\section{Empirical Result}

Fixed effect model is set up in 1) and 2). Cross section weighting is selected. Random effect model is set up in 3). And then three panel regression models containing 7 variables are concluded, which affect the income gap between urban and rural variables. The regression result and coefficients of all variables are seen in Table 1.

Table 1. Regression Result of Panel Data Model

\begin{tabular}{|c|c|c|c|}
\hline GAP & (1) & (2) & (3) \\
\hline $\mathrm{C}$ & $\begin{array}{c}0.112449 * * * \\
(0.008665)\end{array}$ & $\begin{array}{c}0.094421^{* * *} \\
(0.012732)\end{array}$ & $\begin{array}{c}0.069252 * * * \\
(0.012064)\end{array}$ \\
\hline DIFI? & $\begin{array}{c}-0.011671^{* * *} \\
(0.000731) \\
\end{array}$ & $\begin{array}{c}-0.012229 * * * \\
(0.000853)\end{array}$ & $\begin{array}{c}-0.005006^{* * *} \\
(0.000827)\end{array}$ \\
\hline FE? & $\begin{array}{c}0.042930^{* * * *} \\
(0.009899)\end{array}$ & $\begin{array}{c}0.037866 * * * \\
(0.010189)\end{array}$ & $\begin{array}{c}0.035169 * * * \\
(0.010091)\end{array}$ \\
\hline RGDP? & $\begin{array}{c}0.035437 * * * \\
(0.006282)\end{array}$ & $\begin{array}{c}0.041014 * * * \\
(0.007553)\end{array}$ & \\
\hline IS? & $\begin{array}{c}-0.289955 * * * \\
(0.074250)\end{array}$ & $\begin{array}{c}-0.245515^{* * *} \\
(0.07948)\end{array}$ & \\
\hline AFE? & & $\begin{array}{l}0.014637^{*} \\
(0.008728)\end{array}$ & \\
\hline OPEN? & & & $\begin{array}{c}-0.015794 * \\
(0.009546)\end{array}$ \\
\hline URBAN & & & $\begin{array}{c}-0.221235^{* * *} \\
(0.025780)\end{array}$ \\
\hline Adjusted R-squared & 0.997960 & 0.996988 & 0.832893 \\
\hline Model & $\begin{array}{c}\text { Fixed Effect(Cross Section } \\
\text { Weighting) }\end{array}$ & $\begin{array}{c}\text { Fixed Effect(Cross Section } \\
\text { Weighting) }\end{array}$ & Random Effect \\
\hline
\end{tabular}

Three regression results are listed as follows:

$$
\text { GAP }=-0.01 \mathrm{DIFI}+0.04 \mathrm{RGDP}+0.04 \mathrm{FE}-0.29 \mathrm{IS}+0.11 \mathrm{C}
$$

$$
\begin{gathered}
\text { GAP }=-0.01 \mathrm{DIFI}+0.04 \mathrm{RGDP}+0.04 \mathrm{FE}+0.01 \mathrm{AFE}-0.25 \mathrm{IS}+0.09 \mathrm{C} \\
\mathrm{GAP}=-0.005 \mathrm{DIFI}+0.04 \mathrm{FE}-0.02 \mathrm{OPEN}-0.22 \mathrm{URBAN}+0.07 \mathrm{C}
\end{gathered}
$$

Analysis on Empirical Results

The empirical results show that, DIFI AND IS coefficients of all models are negative, which have remarkable effects on narrowing GAP. All FE and RGDP coefficients are positive, which extend the GAP coefficient. Meanwhile, results of Model 2) show that AFE coefficient is positive, which means that the proportion of expenditure for supporting agriculture has the same effects on the income gap between urban and rural residents as that of financial expenditure. Both of them have positive impacts on widening the income gap between urban and rural residents. In Model 3), OPEN and URBAN 
have negative coefficients, which show that the larger the two indicators are, the GAP will be smaller. It conforms to the theoretical expectation.

\section{Conclusion and Strategical Suggestions}

\section{Conclusion}

Influences of Digital Financial Inclusion on Income Gap between Urban and Rural Residents

Judging from the empirical results, it can be seen that, the development of digital financial inclusion will remarkably shorten the income gap between urban and rural residents, which has greatly positive significance for promoting the balanced development between urban and rural development. By the digital technology, digital financial inclusion can be applied to the internet finance and mobile payment. By improving the reachability, cutting off costs and realizing the risk control, it can effectively break through the unbreakable contradiction between profits and cost, further to expand the poverty effects of inclusive finance, weaken the negative threshold and exclusion effects, and then narrow the income gap between urban and rural residents.

Influences of Other Variables on the Income Gap between Urban and Rural Residents

The empirical results show that, the proportion of Chines secondary and tertiary industry, increase of the urbanization level can obviously shorten the income gap between urban and rural residents. It means that, with the progress of industrialization and urbanization, the labor mobility between urban and rural areas has been strengthened. Non-agricultural employees in rural areas are increased, the surplus labor forces are decreased and the per capita productivity has been improved.

The increased financial expenditure proportion and expenditure for supporting agriculture proportion have widened the income gap between urban and rural residents, which shows that, uneven distribution of financial expenditure to the urban and rural areas has brought limitations to the development of rural areas.

The opening-up degree has negative impacts on the income gap between urban and rural residents, which obviously shortens the income gap. It means that, currently, the opening up policy has more positive impacts on the income gap between urban and rural residents than negative impacts.

\section{Strategical Suggestions}

\section{Deepening the Practice of Digital Financial Inclusion}

Development of digital financial inclusion has remarkable impacts on shortening the income gap between urban and rural residents. Digital financial inclusion should be developed vigorously, further to strive no efforts to improve the depth and width of digital financial inclusion, and then improve the construction of financial infrastructures. Corresponding supervision measures should be improved. Peer-to-peer lending, insurance and security on all platforms should be regulated. In the meanwhile of encouraging the deeper development of digital financial inclusion, enterprises and individuals should be avoided to undertake bigger risks. It should vigorously develop commercial banks and digital businesses, and also optimize the affiliated agencies.

Constructing Digital Financial Inclusion Transaction Environment with Scene

In the practice of digital financial inclusion, the most fundamental payments and credit transactions have most direct impacts on the rural areas. There is largest space for playing the role of poverty reduction. By taking advantage of digital technology, transaction platforms with scenario could be constructed, further to make financial services return to essences. The platforms should be embedded in the real productions and transactions, further to better shorten the income gap between urban and rural residents.

Optimizing the External Environment for Developing Digital Financial Inclusion

Empirical analysis shows that, industrialization, urbanization and opening-up degree have remarkable impacts on narrowing the income gap between urban and rural residents. Financial expenditure, expenditure for supporting agriculture proportion, economic development level have enlarged the income gap between urban and rural residents. By optimizing the external factors of 
rural areas, and then integrating it with digital financial inclusion, it can commonly shorten the income gap between urban and rural residents. China should: first of all, it should adopt positive policies of urbanization and industrial structure adjustment, further to eliminate institutional barriers and improve construction of infrastructure. Secondly, it should give full play to their own advantages, further to attract foreign investments. In rural areas, by taking advantage of beneficial environment, resources and corresponding supporting mechanisms, they could attract foreign merchants to build factories locally, so as to seize the opportunity of increasing income. On one hand, the government can offer some policy support to the foreign enterprises which intend to build plants in rural areas, such as tax reduction. On the other hand, it should encourage rural areas to give full play to the local characteristics and optimize the environment, further to offer convenient conditions for the attraction of foreign investments. Thirdly, it should optimize the internal structure of financial expenditure. The government should pay more attention to the expenditure for supporting agriculture, and also conceive the development and construction of rural areas, further to give full play to the guidance of expenditure for supporting agriculture in quantity, distribution and usage efficiency.

\section{Acknowledgments}

This research project is supported by Science Foundation of Beijing Language and Culture University (supported by "the Fundamental Research Funds for the Central Universities") (Approval number 17YJ04004).

\section{References}

[1] Xu Min, Zhang Xiaolin: "Influences of Inclusive Finance on Income Gap Between Urban and Rural Residents", Finance Forum, 2014, the 9th period, Page 9-15.

[2] Zhang Xiaoyan: "Influences of Inclusive Finance on Income Gap Between Urban and Rural Residents under the Background of Internet Finance", Finance and Accounting Monthly, 2016, the 17th period, Page 94-97.

[3] Tang Lizhi, Liu Xihao, Jia Xuan: "Empirical Researches on the Relationship between Financial Development and Income Gap Between Urban and Rural Residents in China", Issues in Agricultural Economy, 2008, the 11th period, Page 44-48.

[4] Lu Min, Chen Zhao: "Economic Policies of Urbanization and Urban Tendency and the Income Gap Between Urban and Rural Residents", Economic Research Journal, 2004, the 6th period, Page 50-58.

[5] Hu Rongcai, Feng Xuzhang: "Influential Factors of Income Gap Between Urban and Rural Residents", China Soft Science, 2011, the 2nd period, Page 69-79.

[6] Hu Jingjing, Huang Hao: "Binary Economic Structure, Governmental Policies and Income Gap Between Urban and Rural Residents", Finance \& Trade Economics, 2013, the 4th period, Page 121-129.

[7] Tian Jie, Tao Jianping: "Influences of Rural Financial Exclusion on Income Gap Between Urban and Rural Residents", Economic Issues in China, 2011, the 5th period, Page 56-64.

[8] Xue Baogui, He Liancheng: "Marketing Competition, Financial Exclusion and Income Gap Between Urban and Rural Residents", Finance and Trade Research, 2016, the 1st period, Page 1-8.

[9] Wang Xiuhua, Qiu Zhaoxiang: "Influential Mechanism of Financial Development in Rural Areas on Income Gap Between Urban and Rural Residents and Empirical Researches", Economic Perspectives, 2011, the 2nd period, Page 71-75. 
[10]Dollar, D. and Kraay, A., "Growth is Good for the Poor," Journal of Economic Growth, Vol.7, No.3, 2002, p.195-225.

[11]Serrano-Cinca, Carlos and B. Gutiérrez-Nieto, "Microfinance, the long tail and mission drift," International Business Review Spain, Vol.23, No.1, 2012, p.181-194.

[12]Bourreau, M. and T. Valetti, "Competition and Interoperability in Mobile Money Platform Markets: What Works and What Doesn’t?" Social Science Electronic Publishing, No.1, 2015, p.1-33. 